\section{Carcinological fauna of Japan}

Crabs of Japan and the Adjacent Seas. By Tune Sakai. Volume 1: English text + figs. Pp. i-xxix +772 . Volume 2; Plates. Pp. 250. Volume 3: Japanese text. Pp. 460. (Kodansha: Tokyo; Antiquariaat Junk: Lochem, The Netherlands, 1976.) Dfl.550 the set.

DuRING the past two decades research on the carcinological fauna of Japan has made rapid progress, resulting in The author of this handsomely produced, up-to-date, and definitive monograph has kept abreast with the recent literature and incorporated the results of over forty years of field work and research. Considerable changes in classification and nomenclature have therefore been madefor example, to the family Potamonidae after Bott, 1970; and to the genus Uca after Crane, 1975.

About 885 species of Brachyura, referable to 329 genera and 30 families, are dealt with taxonomically, and nearly all are illustrated. Numerous keys are given to the determination of most categories from superfamilies to subspecies. Exceptions are, for example, species of Ebalia, which require revision; and genera in the Alliance Xanthoida, because Mme Guinot's investigations are still in progress. Well known species, or ones described in the earlier monograph, many additions to the species of crabs.

Isabella Gordon third volume deals with "subjects". "Periods" will occupy a fourth volume.

The difficulties inherent in this kind of bibliographical synthesis are commensurate with its magnitude. The abbreviations for the journals cited run to seventy- or in The Crabs of Sagami Bay (1965), are not described again.

Throughout, references and synonymies, material examined, habitat with occasional ecological notes, type locality and general distribution, are given. Mention is made of some recently described species not seen by the author. Quite a large percentage are endemic; a few are known only from Japan and some remote locality like Ceylon, or Madagascar. Many are widely distributed throughout the Indo-West Pacific.

Because of the great economic importance of some of the cold water crab-like Anomura of the family Lithodidae, fifteen species (two new to science) are described and illustrated in an Appendix. Bibliographies for the Brachyura and the Lithodidae, and a systematic index, complete the English text. The author's English is always easy to follow, and the Japanese text is apparently intended for the use of students and non-specialists.

The colour plates are excellent. About 600 beautiful paintings after living or frozen crabs, specially prepared by the author's wife, are reproduced: and a number of rather striking colour photographs of crabs in their natural habitats are included. The book will be useful for specialists working on the fauna of the whole of the indo-Pacific region.

Isabella Gordon recently retired after many vears as Head of the Crustacea Section at the British Museum (Natural History), London, UK.

six closely-printed quarto pages. The classification scheme needs ten pages of explanation. That scheme allows the more than twenty thousand entries to be arranged and cross-indexed under approximately seven thousand categories. In an interesting reflection of historical priorities, works on mathematics and the physical sciences occupy one hundred and twenty-three pages to a mere thirty for the biological sciences and twentynine for the sciences of man.

The present volume allows one quickly to identify the reliable historical literature on subjects ranging from "Adsorption: Chemistry" to "Alchemists: North American: Collective Biography", and "University and Advanced Level Teaching: Mathematics: Russia" to "Writing and Reviewing: Science". Like its predecessors, this volume is an indispensable reference work for all those concerned to understand science as a human enterprise.

Arnold Thackray

\section{Underwater optics}

Marine Optics. By N. G. Jerlov. (Elsevier Oceanography Series, No. 14.) Pp. xiii +231 . (Elsevier: Amsterdam, Oxford and New York, 1976.) Dfl.77; $\$ 29.75$.

At first sight this book seems to be a glossier and larger version of Jerlov's Optical Oceanography (Elsevier Oceanography Series, No. 5, 1968); indeed the earlier book is still advertised on the dust cover of the present book, which see.s: a little strange. A closer look shows that the number of figures has increased from 83 to 137 , tables from 28 to 37 , but pages only from 173 to 203 . Impressively, the references have increased from 296 to no less than 548, of which nearly 200 are post-1968. This certainly confirms the author's statement that progress in ocean optics is being made at a rapid rate.

In revising the book the author has eliminated some earlier references and included many others, as well as adding so much new work. In particular one should mention the large number of Russian and eastern European references (about 70) in the recent volume, compared with about 30 in the earlier one. The author's technique in revising has been mainly to repeat word for word the 1968 book, here and there inserting new paragraphs or tagging on bibliographical information. The extra 30 pages are mostly made up by the extra figures and tables.

It should be stressed there is almost no re-writing of the 1968 text and thus it becomes necessary to justify the production (and purchase) of the new volume purely on the extra information included. The price of about $£ 18$ does seem high but the eminence of the author and the assembling of so much extra material probably does justify such expenditure. The new data probably are better shown as figures and tables, but the main advances over the past eight years are more in the nature of additional data built on to old, rather than the formulation of new concepts.

One of the most valuable new sections deals with the use of underwater optics to check the movement of water masses, a valuable tool for the physical orcanographer. As in the 1968 version, however, the author disappoints the biologist reader who is looking for the application of underwater optics to such phenomena as primary production, bioluminescence and animal behaviour.

J. H. S. Blaxter

Arnold Thackray is Chairman of the Department History and Sociology of Science, University of Pennsylvania, and will be a Visiting Fellow at All Souls College, during $1977 .-78$
H S Blaxter is Senior Principal Scientitic Officer at the Scotrish Marine Biological Association. Dunstaffnage Marine Research Lahoratory, Oban. Argyll. 